Article

\title{
Lignin Nanoparticles and Alginate Gel Beads: Preparation, Characterization and Removal of Methylene Blue
}

\author{
Tong Luo ${ }^{1}$, Yanping Hao ${ }^{1}$, Chao Wang ${ }^{1, *}$, Weikun Jiang ${ }^{1}$, Xingxiang Ji ${ }^{1}$, Guihua Yang ${ }^{1}$, Jiachuan Chen ${ }^{1}$, \\ Srinivas Janaswamy $2, *(\mathbb{D})$ and Gaojin Lyu ${ }^{1, *(\mathbb{D})}$
}

1 State Key Laboratory of Biobased Material and Green Papermaking, Qilu University of Technology, Shandong Academy of Sciences, Jinan 250353, China; luotongiant@gmail.com (T.L.); yanpingh2021@gmail.com (Y.H.); weikun0709@126.com (W.J.); jxx@qlu.edu.cn (X.J.); ygh@qlu.edu.cn (G.Y.); chenjc@qlu.edu.cn (J.C.)

2 Department of Dairy and Food Science, South Dakota State University, Brookings, SD 57007, USA

* Correspondence: chaowang@qlu.edu.cn (C.W.); Srinivas.Janaswamy@sdstate.edu (S.J.); gaojinlv@qlu.edu.cn (G.L.); Tel.: +86-0531-8963-1681 (C.W.); +86-0531-8963-1681 (G.L.)

\section{check for}

updates

Citation: Luo, T.; Hao, Y.; Wang, C.; Jiang, W.; Ji, X.; Yang, G.; Chen, J.; Janaswamy, S.; Lyu, G. Lignin Nanoparticles and Alginate Gel Beads: Preparation, Characterization and Removal of Methylene Blue. Nanomaterials 2022, 12, 176.

https://doi.org/10.3390/ nano12010176

Academic Editors: Rosario Gerhardt and Sergio Brutti

Received: 18 November 2021 Accepted: 30 December 2021 Published: 5 January 2022

Publisher's Note: MDPI stays neutral with regard to jurisdictional claims in published maps and institutional affiliations.

Copyright: (C) 2022 by the authors. Licensee MDPI, Basel, Switzerland. This article is an open access article distributed under the terms and conditions of the Creative Commons Attribution (CC BY) license (https:// creativecommons.org/licenses/by/ $4.0 /)$.

\begin{abstract}
A novel and effective green system consisting of deep eutectic solvent (DES) was proposed to prepare lignin nanoparticles (LNPs) without any lignin modification. The LNPs are obtained through the dialysis of the kraft lignin-DES solution. The particle size distribution, Zeta potential and morphology of the LNPs are characterized by using dynamic light scattering (DLS), scanning electron microscopy (SEM) and transmission electron microscopy (TEM). The average diameter of LNPs is in the range 123.6 to $140.7 \mathrm{~nm}$, and the LNPs show good stability and dispersibility in water. The composite beads composed of LNPs and sodium alginate (SA) are highly efficient (97.1\%) at removing methylene blue (MB) from the aqueous solution compared to $82.9 \%$ and $77.4 \%$ by the SA/bulk kraft lignin composite and pure SA, respectively. Overall, the LNPs-SA bio-nanocomposite with high adsorption capacity $(258.5 \mathrm{mg} / \mathrm{g})$ could be useful in improving water quality and other related applications.
\end{abstract}

Keywords: lignin nanoparticles; deep eutectic solvents; sodium alginate; methylene blue; adsorption kinetics

\section{Introduction}

Lignins are natural polymers with aromatic chemical structure possessing methoxy, aldehyde, keto, hydroxyl and phenolic groups [1,2]. They are being extracted from a variety of sources, and large-scale production predominantly arises from the bioethanol and xylose/furfural industries [3,4]. Ironically, around $98 \%$ of lignin from the paper and/or pulp industries is being burned, considering it a waste by-product and non-optimized energy resource $[5,6]$. However, a plethora of applications could be envisioned from lignins, for example, in the synthesis of polymers, dyes and fertilizers, as well as as adhesives in ecological and low-carbon plywood [7]. Their value addition further expands as a green and sustainable source for the design and development of bio-adsorbents, conductive elastomers and packaging membranes [8]. In this regard, the effective valorization of lignin is of great interest, which is further fueled by the shortage of petrochemical resources.

The nonuniform and highly complex chemical structures of lignins also limit their wholesome use. Toward this, tailoring lignin's size to submicron and/or nano scale could be one viable option $[9,10]$. Such a process, indeed, aids to overcome the non-homogeneity of lignin. More importantly, the resulting nano-character coupled with amounts of functional groups, large specific surface area, high diffusibility and compatibility, and low-cost nature opens up novel opportunities for lignins [11,12]. For example, lignin nanoparticles (LNPs) are helpful to fabricate novel and well-performing bio-nanocomposite materials [13-18]. Anti-ultraviolet (UV)/anti-bacterial coatings [19,20], the controlled release of drugs [21,22] and the adsorption of heavy metal ions [23] are a couple of proven examples. 
To date, several protocols, such as sonication, $\mathrm{pH}$ precipitation, chemical crosslinking/polymerization, mechanical treatment and dialysis, on the preparation of LNPs have been developed [24-27]. However, most of these methods demand the chemical modification of lignin using toxic chemicals (e.g., acetyl bromide, pyridine) [12]. The size and shape of the thus prepared LNPs are irregular and aggregate during preparation [17]. In this set, however, dialysis gained special attention due to its simple operation, costeffectiveness and ability to yield spherical LNPs [28]. During this process, lignin is being dissolved in organic solvents such as acetone, dioxane, dimethyl sulfoxide (DMSO) and tetrahydrofuran (THF) [29-32]. However, these are toxic, volatile, flammable and difficult to handle [33]. In addition, dialysis requires the use of larger quantities of solvents. In this regard, a simple method based on green solvents along with environmental friendliness and easy handling is highly desirable, and deep eutectic solvents (DES), formed through the combination of hydrogen bond acceptors (HBA) and hydrogen bond donors (HBD), stand out as viable alternatives. In recent years, DES gained considerable attention as a sustainable solution with high potential to dissolve and valorize lignin [34-39] but with little-to-no exploration of industrial lignins.

Herein, a green and effective approach for LNPs preparation using a novel alkaline DES system without lignin modification has been reported. The structure and morphology of LNPs were investigated using dynamic light scattering (DLS), scanning electron microscopy (SEM) and transmission electron microscopy (TEM). Furthermore, to realize the high-value utilization of LNPs, gel beads have been prepared by combining LNPs with sodium alginate (SA), and their propensity to capture methylene blue (MB) has been demonstrated. Sodium alginate (SA) is an inexpensive natural and abundant polysaccharide. Its non-toxicity, physiological inertness, biocompatibility and biodegradability gained it widespread utility in food and non-food applications [40,41]. The effect of LNPs content, contact time, temperature, dosage of adsorbent and initial $\mathrm{MB}$ concentration on the adsorption have been investigated, along with the adsorption efficiency and release kinetics.

\section{Materials and Methods}

\subsection{Materials}

Kraft lignin (KL) was gift from Huatai Paper Co., Ltd. (Rizhao, China). The chemical composition of lignin is shown in Figure 1 and Table S1. Choline chloride $(\mathrm{ChCl})$, ethanolamine (ETA), sodium alginate (SA), calcium chloride $\left(\mathrm{CaCl}_{2}\right)$ and methylene blue (MB) were purchased from Aladdin Biochemical Technology Co., Ltd. (Shanghai, China). All these reagents were of analytical pure grade and used directly without further processing. Information related to MB dye is shown in Table S2.

DES was prepared according to our previous protocol [42]. Briefly, $\mathrm{ChCl}$ and ETA were used as HBA and HBD, respectively. $\mathrm{ChCl}$ and ETA, at molar ratio of 1:6, were added in a glass vial and heated at $60{ }^{\circ} \mathrm{C}$ with constant stirring to obtain the clear liquid of DES.

\subsection{Preparation of $L N P S$}

LNPs were prepared using the solvent-antisolvent displacement method (dialysis). Briefly, $1.0 \mathrm{~g}$ kraft lignin was dissolved in $20 \mathrm{~g}$ DES with magnetic stirring (600 rpm) for $2 \mathrm{~h}$ at the ambient temperature. Subsequently, the lignin-DES solution was dialyzed $\left(M_{w}=2000\right.$ of dialysis bag $)$ in the deionized water for $72 \mathrm{~h}$, with the periodic replacement of fresh water, to completely remove the DES. After adjusting the concentration (0.1-0.4 wt $\%)$, the LNPs dispersion was stored in a refrigerator $\left(4^{\circ} \mathrm{C}\right)$ for further use. The LNPs powder was obtained after rotary evaporation and freeze-drying. 


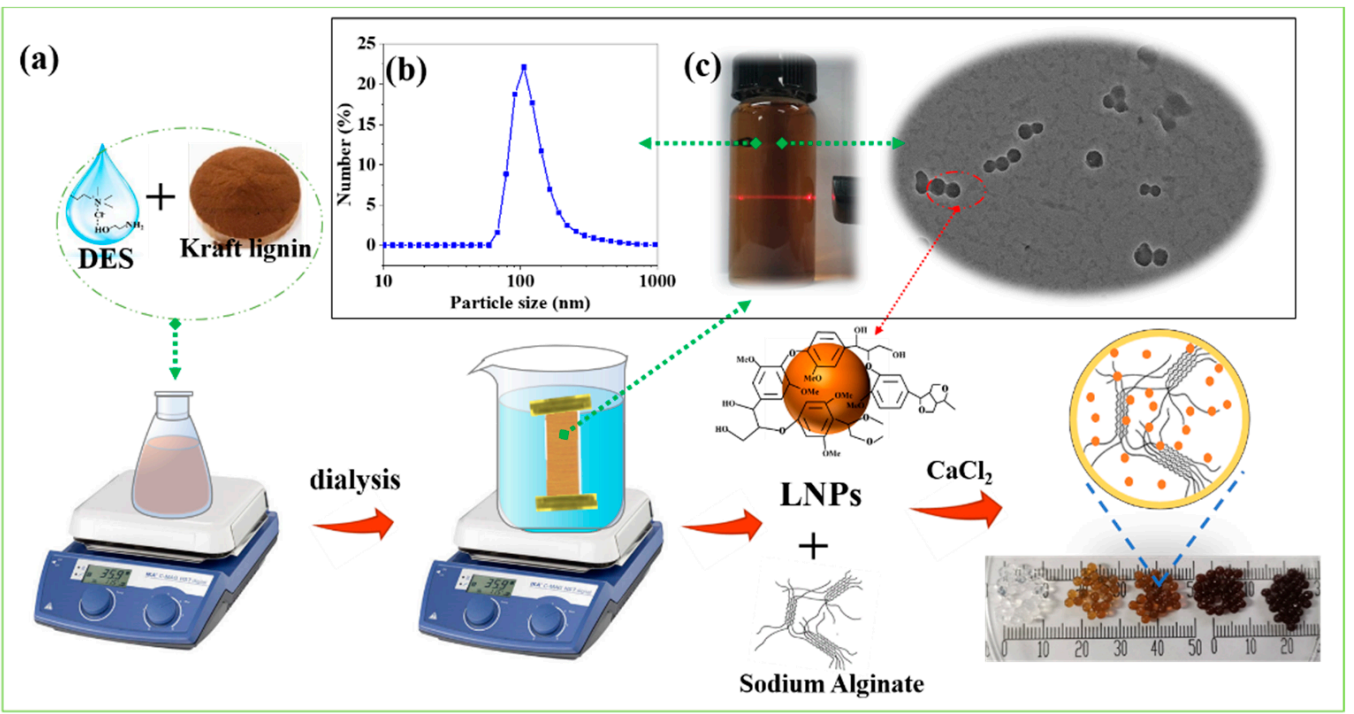

Figure 1. (a) Schematic representation of the preparation procedure for LNPs and SA/LNPs beads; (b) particle-size distribution. (c) The digital photo of the Tyndall effect of the LNPs suspension.

\subsection{Characterization of LNPS}

Transmission electron microscopy (TEM) images were recorded using the JEM2100F TEM (JEM, Japan) with an acceleration voltage of $200 \mathrm{kV}$. Scanning electron microscopy (SEM) observations were carried out on a Regulus 8220 (Hitachi, Japan) at $5 \mathrm{kV}$. The Zeta potential as well as the average particle size of LNPs was investigated with the dynamic light scatterometer from Nano-ZS90, Malvern, UK.

\subsection{Preparation of SA/LNPS Composite Bead}

Composite gel beads were prepared by mixing SA and LNPs (Figures 1 and S1). A certain amount of SA powder was added into different LNPs dispersions to get a concentration of $1 \mathrm{wt} \%$ mixture under constant stirring at ambient temperature for $3 \mathrm{~h}$. Subsequently, the mixture was added dropwise to the $\mathrm{CaCl}_{2}$ solution $(0.1 \mathrm{M})$. The beads were formed immediately and cured for $12 \mathrm{~h}$. After washing with deionized water and removing the excess $\mathrm{Ca}^{2+}$, the SA/LNPs beads were used for adsorption experiments. A few were also freeze-dried for further characterization. The details about the SA/LNPs gel beads and corresponding chemical composition are listed in Table 1. The samples were coded as SA/LNP-xx, for brevity. For example, SA/LNP-40 represent beads with LNPs content of $40 \mathrm{wt} . \%$. The SA/L-40 beads served as the control group that were prepared by mixing kraft lignin with sodium alginate.

Table 1. Chemical composition of the SA/LNPs composite gel beads.

\begin{tabular}{ccccc}
\hline Sample & $\mathbf{H}_{\mathbf{2}} \mathbf{O}(\mathbf{m L})$ & $m_{\mathbf{S A}}(\mathbf{g})$ & $m_{\text {LNPs }}(\mathbf{g})$ & $m_{\text {LNPs }} /\left(\mathbf{m}_{\mathbf{L N P s}}+\mathbf{m}_{\mathbf{S A}}\right)$ \\
\hline SA & 100 & 1 & 0 & 0 \\
SA/LNPs-10 & 100 & 0.9 & 0.1 & $10 \%$ \\
SA/LNPs-20 & 100 & 0.8 & 0.2 & $20 \%$ \\
SA/LNPs-30 & 100 & 0.7 & 0.3 & $30 \%$ \\
SA/LNPs-40 & 100 & 0.6 & 0.4 & $40 \%$ \\
\hline
\end{tabular}

\subsection{Characterization of $S A / L N P S$ Composite Beads}

Surface morphology of the SA/LNPs gel beads was investigated with the SEM Regulus 8220 from Hitachi, Japan. The chemical compositions of the gel beads were assessed by FT-IR spectroscopy from Bruker, ALPHA, Germany in the scanning range of $4000-500 \mathrm{~cm}^{-1}$ at a resolution of $4 \mathrm{~cm}^{-1}$. Thermogravimetric analysis (TGA) of the SA powder and gel 
beads was carried out with the Q50 thermogravimetric analyzer from TA Instruments, New Castle, DE, USA.

\subsection{Removal Efficiency of the Composite Gel Beads}

A predetermined amount of gel beads was dispersed in the MB aqueous solution of $50 \mathrm{~mL}$. The mixture was then incubated in an air bath constant temperature shaker with constant stirring for a given time. The MB concentrations was detected by the UV-visible spectrophotometer UV-2600 from Shimadzu, Japan, at $664 \mathrm{~nm}[43,44]$. The corresponding adsorption capacity $\left(q_{e}, \mathrm{mg} / \mathrm{g}\right)$, adsorption capacity at time $t\left(q_{t}, \mathrm{mg} / \mathrm{g}\right)$ and the removal rate $(\varphi, \%)$ were calculated using the following three equations.

$$
\begin{gathered}
q_{e}=\frac{\left(C_{0}-C_{e}\right) V}{\mathrm{~m}} \\
q_{t}=\frac{\left(C_{0}-C_{t}\right) V}{\mathrm{~m}} \\
\varphi=\frac{C_{0}-C_{e}}{C_{0}} \times 100 \%
\end{gathered}
$$

Herein, $C_{0}(\mathrm{mg} / \mathrm{L})$ represents the initial concentration of dye. The $C e$ and $C_{t}(\mathrm{mg} / \mathrm{L})$ refer the concentration at adsorption equilibrium and at adsorption time $t$, respectively. The $V$ (measured in $L$ ) is the volume of the solution and $m$ (measured in $g$ ) the mass of the composite beads.

\subsection{Kinetic Modelling and Isotherms}

Four models namely Lagergren's pseudo-first-order, pseudo-second-order and intraparticle diffusion were used to describe the adsorption process. The corresponding equations Equations (S1)-(S3), respectively, are listed in the support material. The adsorption isotherms are represented by the Langmuir, Freundlich and Temkin isotherm equations (Equations (S4)-(S6), respectively). The fundamental properties of Langmuir isotherm could be illustrated by a dimensionless constant $R_{L}$, known as separation factor, with the Equation (S7).

\section{Results and Discussion}

\subsection{LNPs Prepared by Dialysis in a $\mathrm{ChCl} \&$ ETA System}

Lignin contains both hydrophobic units and hydrophilic functional groups, and thus it is generally considered as an amphiphilic biopolymer [45]. This structure makes it possible for lignin to form uniform hydrophilic nano-micelles in aqueous solutions [46]. DES has been proven to solubilize lignin effectively [47-49], and $\mathrm{ChCl}$ and ETA are the most promising candidates for industrial applications because of their low viscosity, environmentally friendly and biodegradable nature. In this regard, herein we propose DES composed of $\mathrm{ChCl}$ and ETA as a novel dissolution system for the LNPs preparation. The unmodified kraft lignin was first dissolved in DES, and then subjected to dialysis in plenty of fresh water at the ambient temperature. During this process, lignin solubility decreases but with the LNPs formation. The forces that contribute to LNPs development include hydrophobic, hydrogen bonding and $\pi$-interactions along with van der Waals forces [10,50]. The resulting LNPs suspension is a uniform solution that readily displays the Tyndall effect (Figure 1c).

The mean particle diameter and size distribution of the LNPs are analyzed via a particle-size-versus-fraction distribution plot. The LNPs have a size of $60-200 \mathrm{~nm}$ (Figure 1b). The concentration of LNPs suspension did not affect the particle size, and the average is in the range of 123.6 to $140.7 \mathrm{~nm}$ for the 0.1 to $0.4 \%$ concentration (Figure S2). The SEM and TEM images are shown in Figure 2c,d, respectively. The initial kraft lignin particles possess an irregular shape with a micron size, but the prepared LNPs have more of a spherical morphology with a narrow nano-size distribution that was maintained even after freeze-drying (Figure 2). It can be seen that there are particle-size differences between 
the SEM/TEM and DLS studies. It may be because, in the process of dialysis, LNPs formed gradually in the aqueous medium with a hydrophilic surface and maintained the electrostatic stability with the presence of weak carboxyl groups of lignin that preclude particle aggregation, resulting in particles of average size. However, small amounts of LNPs could accumulate during the drying process of micromorphology analysis, resulting in a subtle increase in the particle size $[17,32]$.

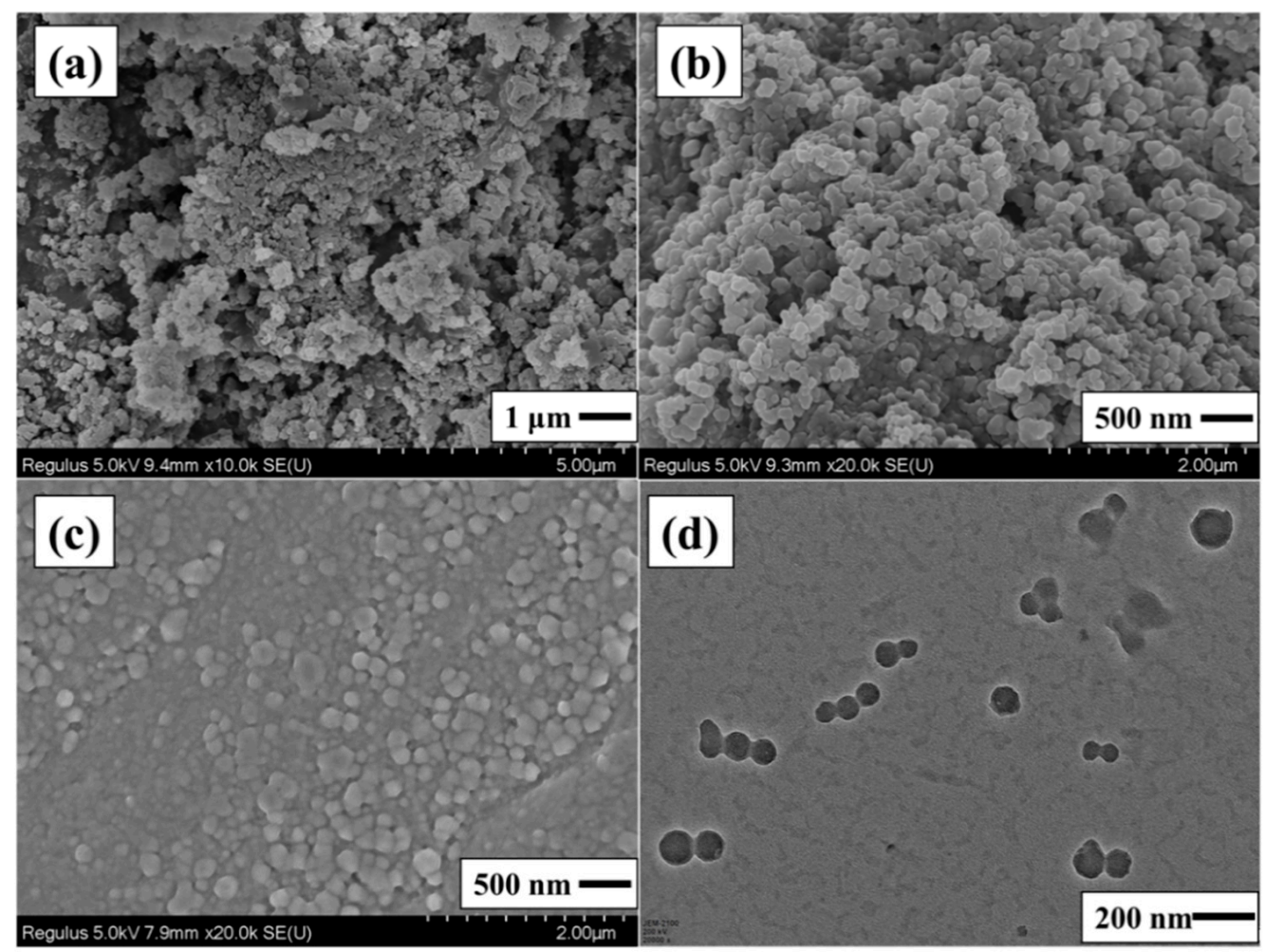

Figure 2. SEM images of the (a) lignin, (b) freeze-dried LNPs, (c) LNPs dispersions and (d) TEM images of the LNPs dispersions.

The stability of LNPs is an important factor that influences their performance [51]. In order to evaluate LNPs, Zeta potential and average diameter are measured as a function of time. Interestingly, Zeta potential and the average diameter of LNPs change slightly (Figure 3) from $-39.2 \mathrm{mV}$ to $-37.6 \mathrm{mV}$ and from $133.2 \mathrm{~nm}$ to $144 \mathrm{~nm}$ during 30 days storage, respectively, portraying their stability in water. The high Zeta potential value clearly suggests that the ionizing groups and hydrophilic groups of LNPs are exposed on the nanoparticle surface, and the resulting strong repulsive forces prevent the LNPs aggregation, which certainly is advantageous [52,53]. The observed stability further hints that these LNPs could be explored as additives and stabilizers [54]. Overall, the regular spherical morphology, uniform particle size and high stability of these LNPs make them as promising candidates for the production of polymer nanocomposites but warrants further study.

\subsection{Characterization of the Composite Gel Beads}

The SA/LNPs composite beads are prepared by using a simple blending protocol. The addition of the LNPs/SA mixture into the $\mathrm{Ca}^{2+}$ solution improves the stability of the colloids (Figure S1). Thus, the introduction of LNPs into the alginate beads could improve their adsorption and thermal performance as well. The SEM images of the freezedried beads are shown in Figure 4. The SA beads display a smooth surface, but the incorporation of LNPs results in a corrugated surface (Figure 4d). Figure 5 highlights the FT-IR spectra of LNPs, SA beads and SA/LNPs-40 beads. In the LNPs, characteristic peaks 
at $1460 \mathrm{~cm}^{-1}$ correspond to the vibration of $\mathrm{C}-\mathrm{H}$ deformation of lignin [55]. The peaks at $1508 \mathrm{~cm}^{-1}$ and $1024 \mathrm{~cm}^{-1}$ are due to $\mathrm{C}-\mathrm{C}$ aromatic skeletal vibration and $\mathrm{C}-\mathrm{O}$ stretching, respectively $[56,57]$. Compared with the pure SA beads, a new peak at $1508 \mathrm{~cm}^{-1}(\mathrm{C}-\mathrm{C}$ aromatic skeleton) in the SA/LNPs-40 beads suggest LNPs successful incorporation within the SA matrix.

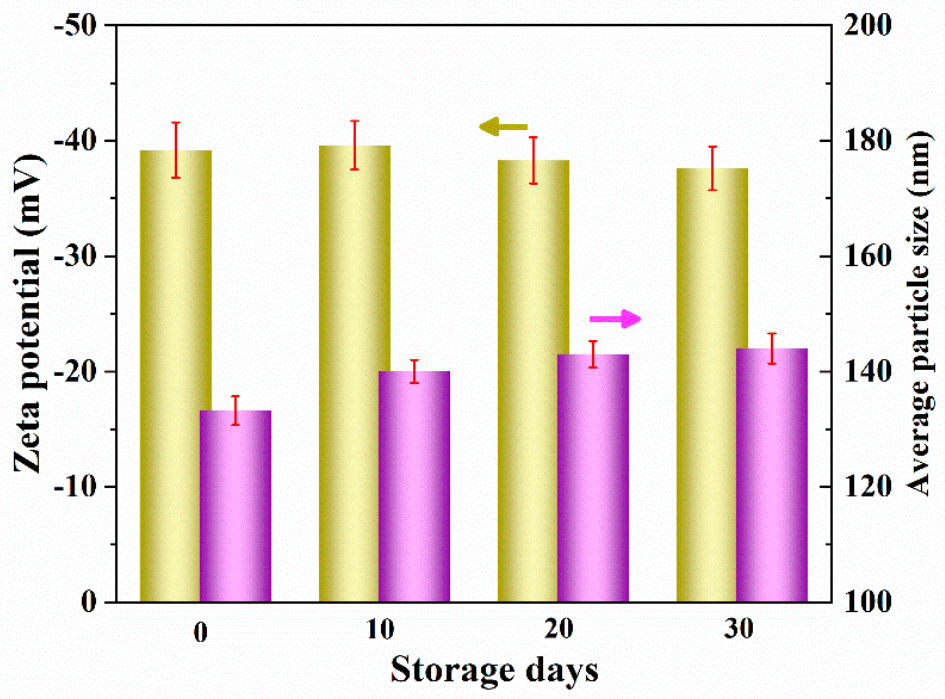

Figure 3. Average particle size and Zeta potential of the LNPs dispersions stored for 30 days.

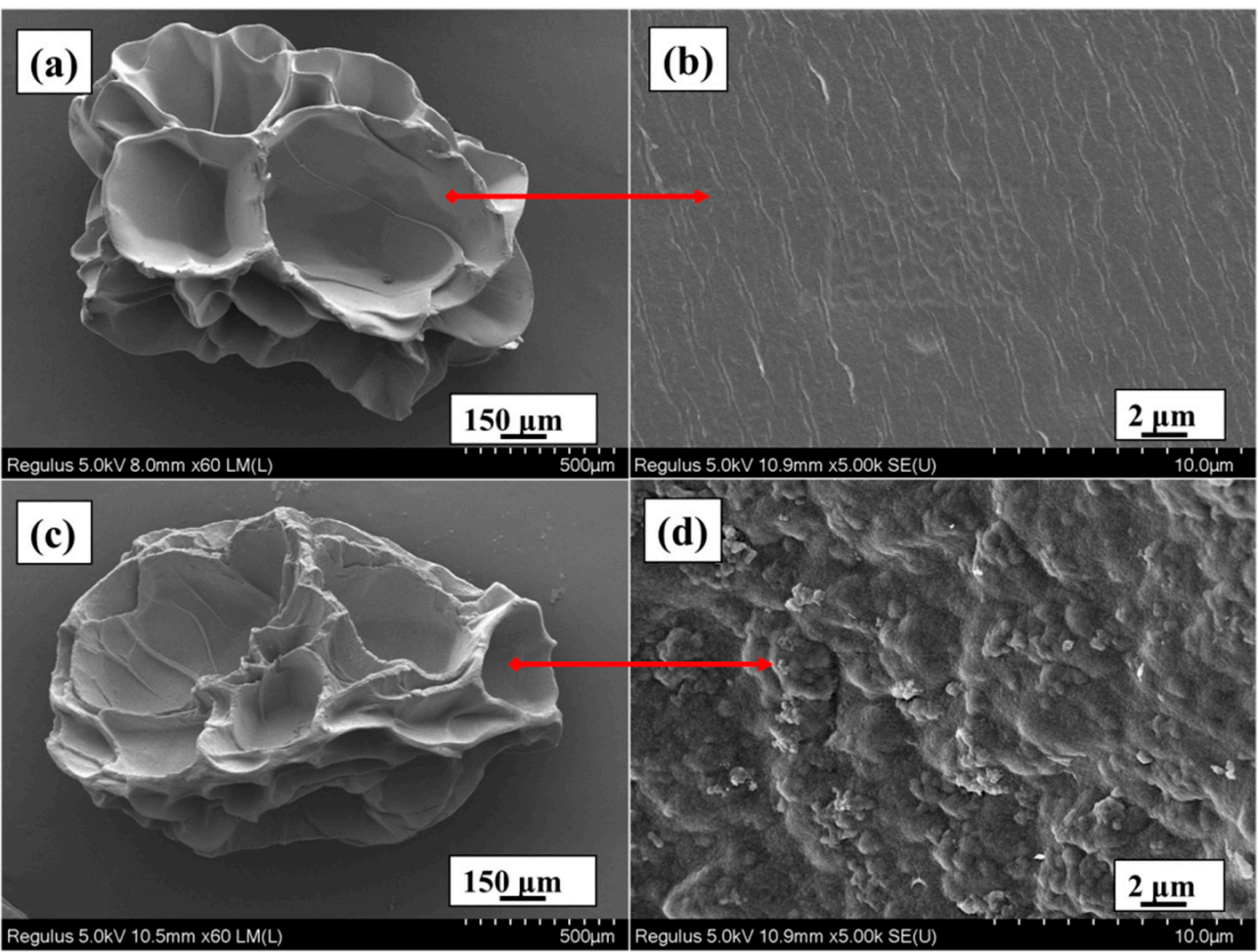

Figure 4. SEM images of the freeze-dried $(\mathbf{a}, \mathbf{b})$ SA beads and (c,d) SA/LNPs-40. 


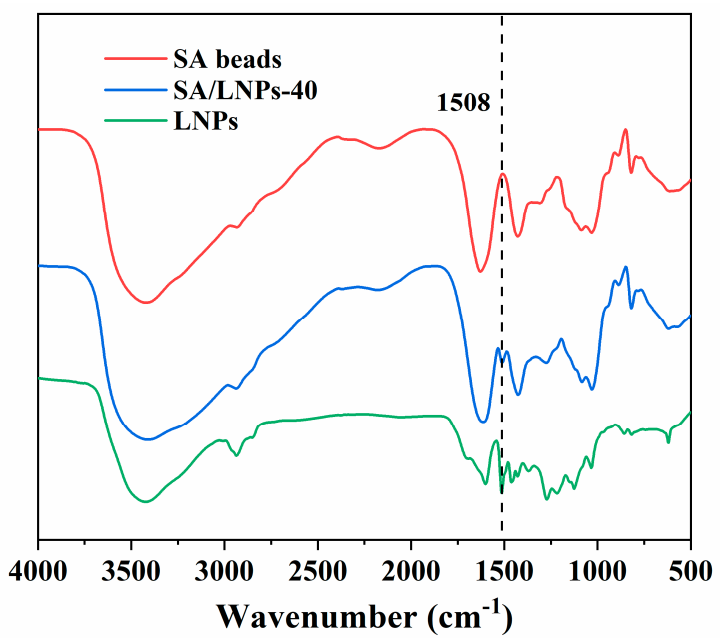

Figure 5. Comparison of the FT-IR spectra of LNPs, SA and SA/LNPs-40 beads.

The TG and DTG measurements are used to evaluate the thermal stability of the SALNPs composite beads. The thermal curves of SA powder, pure SA beads and composites beads with varying LNPs amount are shown in Figure 6 . The initial degradation $\left(T_{i}\right)$ and maximum degradation $\left(T_{\max }\right)$ temperature, along with the parameters of thermal stability, are compared in Table S3. The SA powder exhibits single-step degradation with a high $T_{\max }$ of $259.3{ }^{\circ} \mathrm{C}$, and the maximum rate reached is $1.59 \mathrm{wt} \% /{ }^{\circ} \mathrm{C}$. In contrast, composite beads exhibit relatively lower thermal decomposition temperature but with two degradation peaks, suggesting that the pyrolysis of composite beads could be divided into two steps. As the content of LNPs increases from 0 to $40 \%$, the $T_{i}$ and $T_{\max }$ raise from 225.3 to $239.2{ }^{\circ} \mathrm{C}$ and from 233.7 to $258.6^{\circ} \mathrm{C}$, respectively, but the maximum degradation rate decreases from 0.47 to $0.23 \mathrm{wt} \% /{ }^{\circ} \mathrm{C}$. The SA powder displays the least residue, of $33.7 \%$, which increases with the addition of LNPs to 37.1-48.5\% (Table S3). Overall, the thermal stability of SA beads improves with the incorporation of LNPs, presumably due to the formation of a cross-linked and/or condensed aromatic matrix [58].
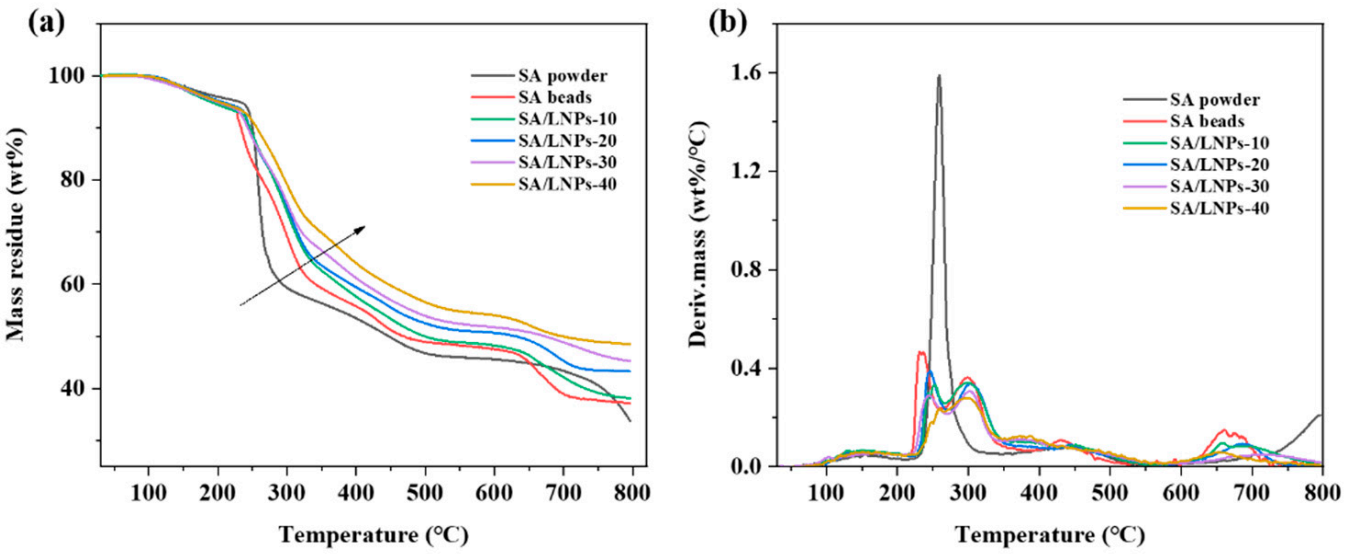

Figure 6. (a) TGA and (b) DTG curves of SA powder and composite beads.

\subsection{Important Factors Affecting Adsorption}

In recent years, biopolymers derived from biomass and natural materials have attracted research interest due to their low cost, ease of preparation and effective wastewatertreatment attributes $[59,60]$. In particular, their intrinsic ability to cleanup wastewater dyes that are toxic and carcinogenic has become an important environmental tool. Herein, the main mechanism for MB (cationic dyes) adsorption would be due to electrostatic interactions between the MB's cationic groups and the carboxyl groups of the polysaccharide and the functional groups of lignin. The formation of hydrogen bonding and $\pi$-interactions 
could not be discounted, however [61]. The suggested mechanism of interactions between the dye and beads is highlighted in Figure S3. As it is well known that the adsorption efficiency depends on the physical and chemical properties of the adsorbent and dye, as well as the adsorption conditions such as time, temperature, dye and adsorbents concentration, etc. [62], the optimization of these parameters has been carried out to best accomplish the removal of MB by the SA-LNP beads.

\subsubsection{Effect of LNPs Content}

Interestingly, the proportion of LNPs could reach 40\% without using any crosslinking agent. Further increase reduces the viscosity of the mixture and precludes bead formation in the calcium chloride solution. As seen from Figure 7b, it is clear that, with increase in the LNP content, the color of the MB solution gradually turns pale upon adsorption. This hints that the mass ratio of LNPs and SA had a great effect on the adsorption performance by the composite beads. The removal efficiency and adsorption capacity of the composite beads with different proportions for MB are shown in Figure 7a. The adsorption amount increases gradually with the LNPs amount. The equilibrium removal rate of SA/LNPs-40 beads reaches to $97.1 \%$ compared to $82.9 \%$ and $77.4 \%$ of SA/L and SA, respectively. Such an increase could be ascribed to the presence of LNPs in the beads [12].

(a)

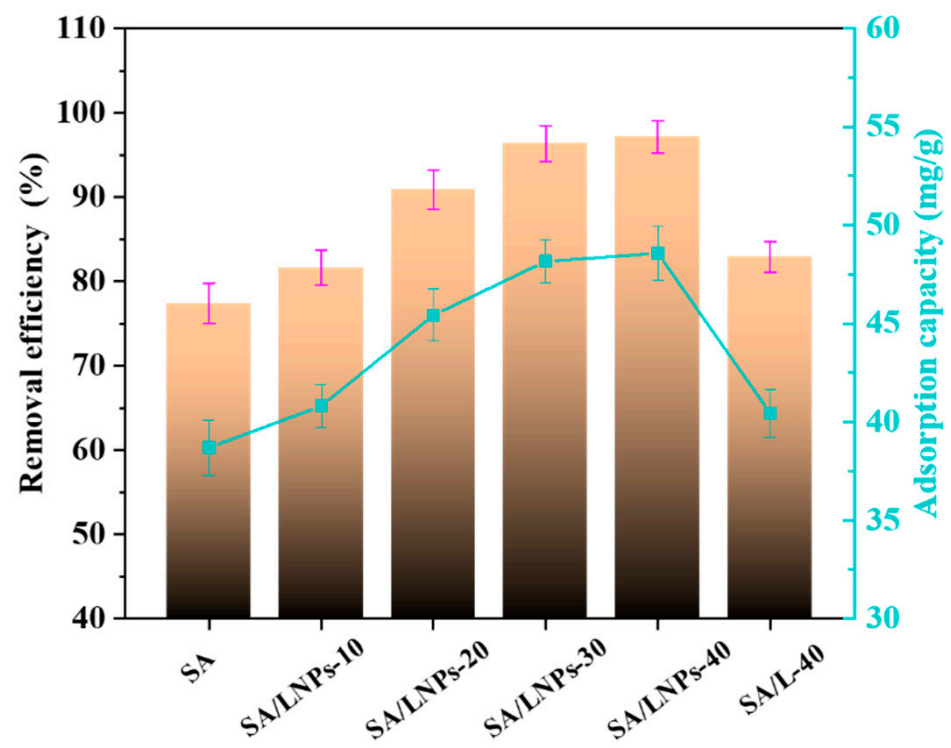

(b)

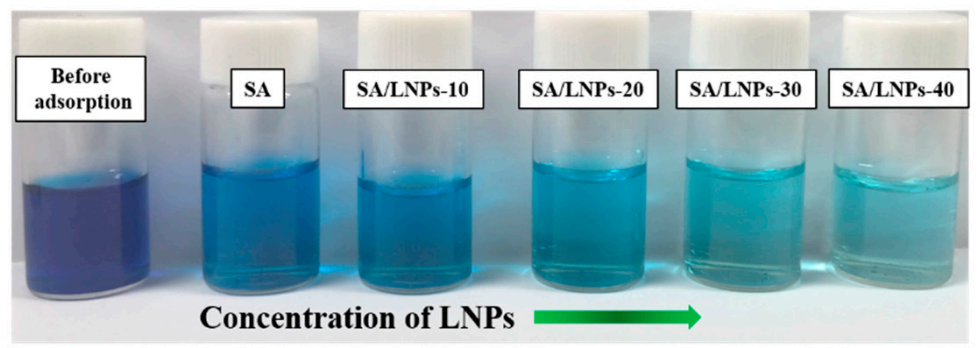

Figure 7. (a) Removal efficiency and adsorption capacity of MB by the SA-LNP composite beads with different LNPs content (2.0 g/L beads, $\left.50 \mathrm{~mL} 100 \mathrm{mg} / \mathrm{L} \mathrm{MB}, 150 \mathrm{rpm}, 25{ }^{\circ} \mathrm{C}, 2 \mathrm{~h}\right)$, (b) Digital images of methylene blue absorbed by the SA-LNP beads with LNPs amount.

\subsubsection{Effect of Contact Time}

The adsorption capacity increases rapidly with time and later slows down to reach equilibrium at about 120 min (Figure 8a). Herein, Lagergren's pseudo-first and secondorder, as well as the intraparticle diffusion models, are tested to understand the release kinetics (Table S4). In the case of SA and SA/LNPs-40 beads, the pseudo-second order 
model yielded a more accurate prediction with $R^{2}>0.99$ than that of the pseudo-first-order model $\left(R^{2} \sim 0.91\right)$. The calculated $q_{e} 48.5 \mathrm{mg} / \mathrm{g}$ highly matches with the experimental value of $48.6 \mathrm{mg} / \mathrm{g}$. The observed pseudo-second-order kinetics suggests that the adsorption is of a chemical process with active forces between the MB and SA/LNPs-40 beads. The plot of $q_{t}$ vs. $t^{1 / 2}$ is highlighted in Figure $8 \mathrm{~d}$. The $K_{p}$ estimated based on the slope of the each fitted straight-line and the $R^{2}$ of SA/LNPs-40 for the step 1, step 2 and step 3 is 2.637, 0.647

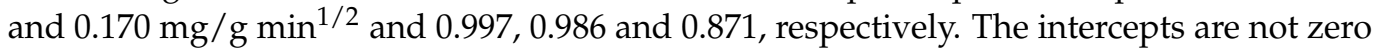
(Figure $8 \mathrm{~d}$ ), suggesting the occurrence of boundary layer diffusion. It further implies that intra-particle diffusion is not the only speed-control step during the MB adsorption, but it is more complicated $[10,56]$.
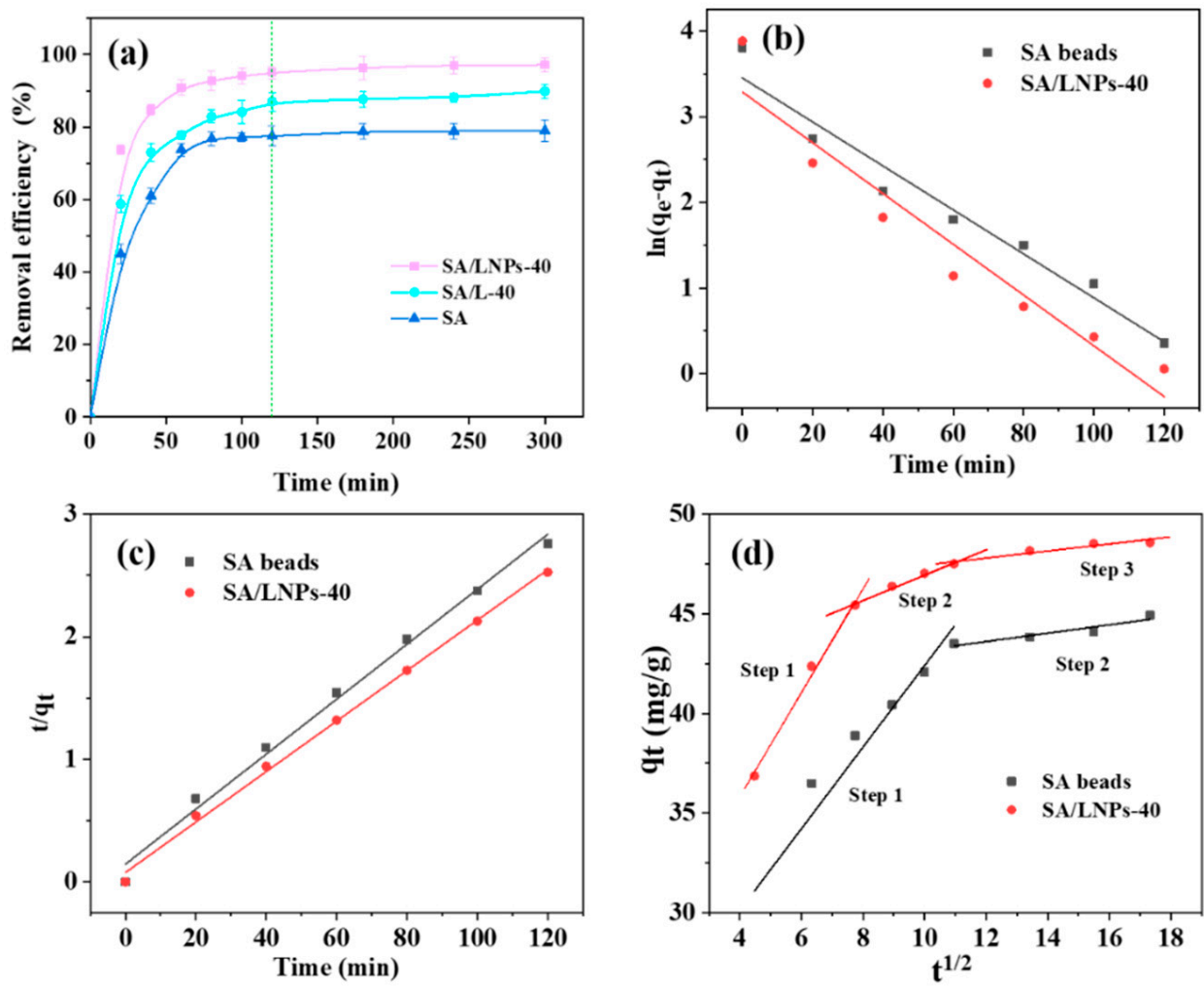

Figure 8. (a) The removal efficiency of different adsorption times $(2.0 \mathrm{~g} / \mathrm{L}$ beads, $50 \mathrm{~mL} 100 \mathrm{mg} / \mathrm{L}$ $\mathrm{MB}, 150 \mathrm{rpm}, 25^{\circ} \mathrm{C}$ ); adsorption kinetics, linear fitting of (b) pseudo-first- and (c) pseudo-secondorder kinetic models of SA and SA/LNPs-40 beads and (d) the intra-particle diffusion model of SA/LNPs-40 beads.

\subsubsection{Effect of Adsorbents Dosage}

It could be seen from Figure 9a that the average capacity of MB adsorption decreases with increases in the adsorbent amount, while the removal rate surges and approaches the complete removal. The rise in the removal efficiency could be attributed to the presence of additional adsorption sites and the contact area provided by the higher bead content [63]. However, adsorption capacity decreases with increases of bead dosage, suggesting the generation of substantial unsaturated adsorption sites in the beads [64]. 

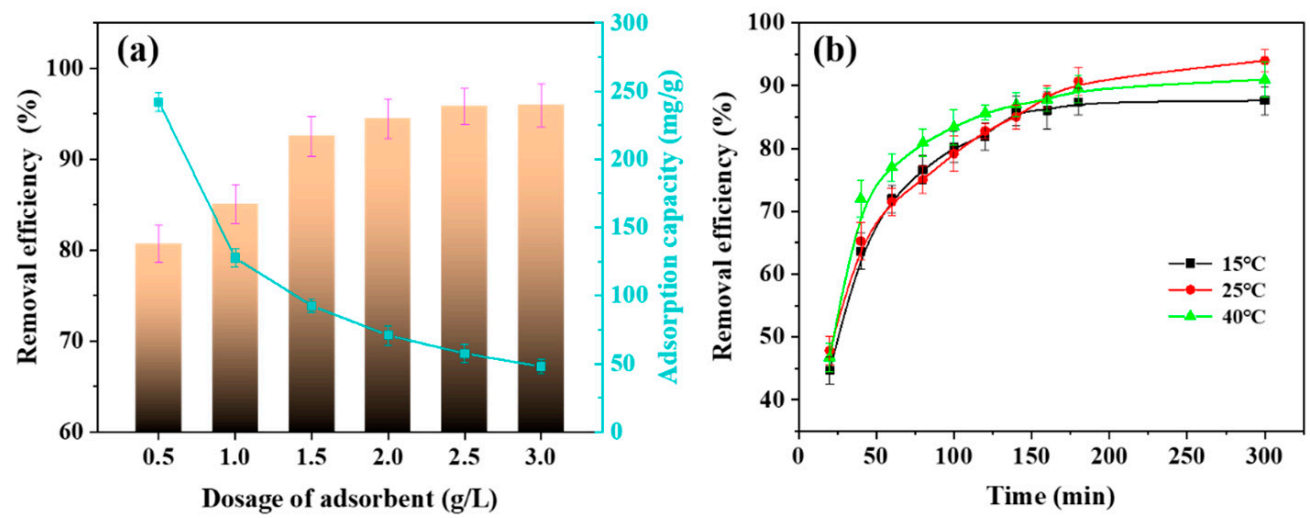

Figure 9. (a) The removal efficiency and adsorption capacity with different dosage of adsorbent (0.5-3.0 g/L SA/LNPs-40, $50 \mathrm{~mL} 150 \mathrm{mg} / \mathrm{L} \mathrm{MB}, 150 \mathrm{rpm}, 25^{\circ} \mathrm{C}, 3 \mathrm{~h}$ ). (b) Removal efficiency of different temperature (2.0 g/L SA/LNPs-40, $50 \mathrm{~mL} 150 \mathrm{mg} / \mathrm{L} \mathrm{MB}, 150 \mathrm{rpm}, 15,25$ and $\left.40{ }^{\circ} \mathrm{C}, 6 \mathrm{~h}\right)$.

\subsubsection{Effect of Temperature}

Figure $9 \mathrm{~b}$ shows the effect of temperature on the removal efficiency. The removal rate is high at $2{ }^{\circ} \mathrm{C}$, with a rate of $94.6 \%$, followed by 91.0 and $87.6 \%$ at $40{ }^{\circ} \mathrm{C}$ and $15^{\circ} \mathrm{C}$, respectively. At the lower temperature of $15^{\circ} \mathrm{C}$, the kinetic energy of $\mathrm{MB}$ molecules appears to be insufficient, and thus, the rate of diffusion from the aqueous solution to the surface of the composite beads is slow. However, with the temperature rise to $40^{\circ} \mathrm{C}$, the movement rate of $\mathrm{MB}$ increases, and consequently, it would be easy for the $\mathrm{MB}$ molecules to reach the surface of the SA/LNPs beads. Although the number of MB molecules reaching the adsorption site increases, high temperature reduces forces, e.g., hydrogen bonds, between the adsorbent adsorption sites and MB molecules. Due to increases in the kinetic energy, MB molecules that are adsorbed on to the surface of the beads are desorbed, resulting in the observed decrease in the overall adsorption efficiency [61].

\subsubsection{Effect of Initial Concentration of MB}

The effects of initial MB concentrations on the adsorption process under fixed amounts of SA/LNPs beads are studied, and corresponding plots are shown in Figure 10a. It indicates that the adsorption capacity of the SA/LNPs beads increases with the MB concentration. As the $\mathrm{MB}$ concentration upsurges from $50 \mathrm{mg} / \mathrm{L}$ to $800 \mathrm{mg} / \mathrm{L}$, the adsorption quality of MB by the SA/LNPs-40 beads increases from $23.7 \mathrm{mg} / \mathrm{g}$ to $258.5 \mathrm{mg} / \mathrm{g}$, indicating that the adsorption capacity is concentration-dependent, which could be due to higher contact probability and stronger forces between the SA/LNPs and MB molecules [65]. In order to study the adsorption process, three isotherm models, i.e., Langmuir, Freundlich and Temkin, have been tested. The model fitting curves and associated parameters are shown in Figure 10b-d and Table S5. The Langmuir $\left(R^{2} \sim 0.978\right)$ and Freundlich isotherm models $\left(R^{2} \sim 0.988\right)$ yield better fitting than the Temkin $\left(R^{2} \sim 0.764\right)$. The Freundlich model with $n>1$ illustrates that highly favorable adsorption with strong intensity. Similarly, as per the Langmuir fitting, the maximum adsorption capacity $\left(q_{m}\right) 276.1 \mathrm{mg} / \mathrm{g}$ of $\mathrm{MB}$ is quite similar to the experimental observation of $258.5 \mathrm{mg} / \mathrm{g}$. In addition, the $R_{L}$ value between 0 and 1 implies that the adsorption of MB onto the SA/LNPs beads is highly favorable [66,67]. 

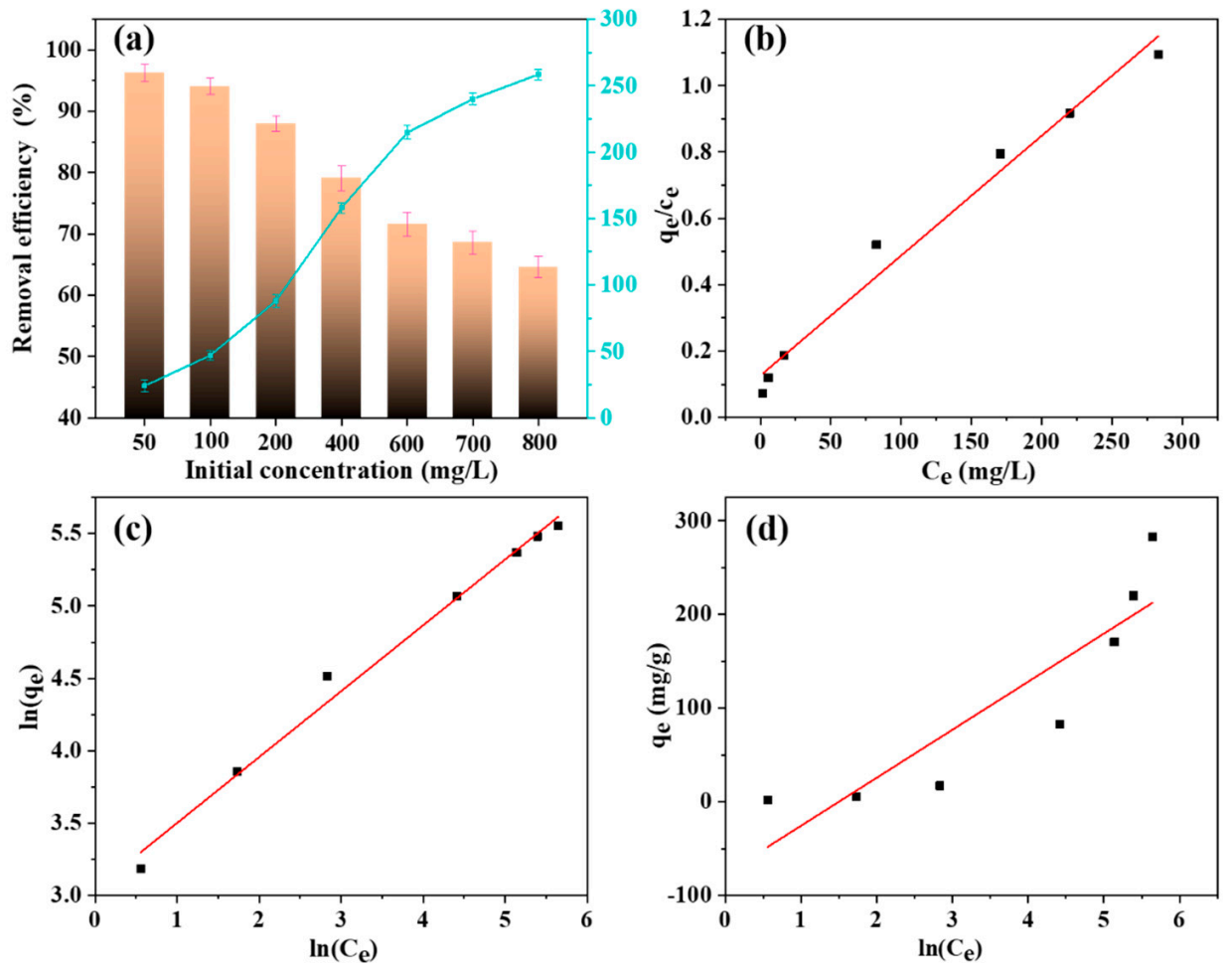

Figure 10. (a) The removal efficiency and adsorption capacity of SA/LNPs beads at different initial concentrations. (b) The Langmuir, (c) Freundlich and (d) Temkin model isotherms for the adsorption of MB onto the SA/LNPs-40 beads (2.0 g/L SA/LNPs-40, $50 \mathrm{~mL} 50-800 \mathrm{mg} / \mathrm{L} \mathrm{MB}, 150 \mathrm{rpm}, 25^{\circ} \mathrm{C}$, $3 \mathrm{~h})$.

Overall, SA/LNPs beads are promising, eco-friendly and effective adsorbents of MB and could as well be applicable to other dyes. The Table 2 compares the adsorption capacities of MB by some lignocellulosic-based materials, and SA/LNPs beads are comparable to cellulose nanocrystal-alginate hydrogel beads. The outcome could be easily translated to other biowastes, for example, paper industry wastes toward generating value-addition of lignin.

Table 2. Adsorption capacities of MB by lignocellulosic-based materials reported in literatures.

\begin{tabular}{ccc}
\hline Adsorbent & $\boldsymbol{q}_{\max }(\mathbf{m g} / \mathbf{g})$ & Reference \\
\hline Chitosan/nano-lignin composite & 74 & {$[10]$} \\
Activated lignin-chitosan extruded blends & 36 & {$[43]$} \\
Lignin-silica hybrid composites & 60 & {$[44]$} \\
Cellulose nanocrystal-alginate hydrogel beads & 256 & {$[67]$} \\
SA/LNPs beads & 258.5 & This study \\
\hline
\end{tabular}

\section{Conclusions}

In this study, lignin nanoparticles (LNPs) have been prepared from kraft lignin using the alkaline deep eutectic solvent (DES) system without chemical modification. The obtained LNPs are spherical, with a size range of 123.6 to $140.7 \mathrm{~nm}$. These LNPs are then fabricated into nanocomposite gel beads using a sodium alginate (SA) matrix to remove methylene blue (MB) from the aqueous solution. Adsorption studies reveal strong electrostatic interactions, hydrogen bonding and $\pi$-interactions between MB molecules (cationic group) and SA/LNPs (anionic functional groups), resulting in the enhanced adsorption of MB (258.5 mg/g). The outcome paves the way for further studies on the design and development of sustainable nano-lignin-based biomaterials for large-scale and industrial applications, e.g., wastewater-purification systems. 
Supplementary Materials: The following are available online at https:/ / www.mdpi.com/article/ 10.3390/nano12010176/s1: Figure S1: Proposed mechanism of MB interactions between the dye and the LNPs; Figure S2: (a) Digital images of LNPs suspension with different concentrations and (b) average particle-size distribution of LNPs at different concentrations of aqueous solution; Figure S3: Mechanisms of cross-linking of LNPs and SA; Table S1: The chemical composition of lignin; Table S2: The information related to MB dye; Table S3: TGA results of SA/LNPs composite beads; Table S4: Parameters of various adsorption kinetic models; Table S5: Isotherm model parameters for adsorption.

Author Contributions: Conceptualization, C.W. and G.L.; Methodology, T.L., Y.H., X.J. and G.L.; Software, T.L. and W.J.; Visualization, C.W. and G.Y.; Formal analysis, T.L., C.W. and S.J.; WritingOriginal Draft, T.L., Y.H. and C.W.; Writing-Review and Editing, J.C., G.L. and S.J.; Supervision, G.L. All authors have read and agreed to the published version of the manuscript.

Funding: This research was funded by the National Natural Science Foundation of China, grant number 31770630; 32001275; China Postdoctoral Science Foundation, grant number 2019M652387; Taishan Scholars Program of Shandong Province and USDA National Institute of Food and Agriculture, grant number SD00H648-18.

Institutional Review Board Statement: Not applicable.

Informed Consent Statement: Not applicable.

Data Availability Statement: The data presented in this study are available in this article.

Acknowledgments: The authors are grateful for the support of the National Natural Science Foundation of China (Grant No. 31770630; 32001275), China Postdoctoral Science Foundation (Grant No. 2019M652387), Taishan Scholars Program of Shandong Province and USDA National Institute of Food and Agriculture (SD00H648-18).

Conflicts of Interest: The authors declare no conflict of interest.

\section{References}

1. Yu, C.; Wang, F.; Zhang, C.; Fu, S.; Lucia, L.A. The synthesis and absorption dynamics of a lignin-based hydrogel for remediation of cationic dye-contaminated effluent. React. Funct. Polym. 2016, 106, 137-142. [CrossRef]

2. Ragauskas, A.J.; Beckham, G.T.; Biddy, M.J.; Chandra, R.; Chen, F.; Davis, M.F.; Davison, B.H.; Dixon, R.A.; Gilna, P.; Keller, M.; et al. Lignin Valorization: Improving Lignin Processing in the Biorefinery. Science 2014, 344, 1246843. [CrossRef] [PubMed]

3. Sun, Z.; Fridrich, B.; de Santi, A.; Elangovan, S.; Barta, K. Bright Side of Lignin Depolymerization: Toward New Platform Chemicals. Chem. Rev. 2018, 118, 614-678. [CrossRef]

4. Chiappero, L.R.; Bartolomei, S.S.; Estenoz, D.A.; Moura, E.A.B.; Nicolau, V.V. Lignin-Based Polyethylene Films with Enhanced Thermal, Opacity and Biodegradability Properties for Agricultural Mulch Applications. J. Polym. Environ. 2021, 29, 450-459. [CrossRef]

5. Huang, D.; Li, R.; Xu, P.; Li, T.; Deng, R.; Chen, S.; Zhang, Q. The cornerstone of realizing lignin value-addition: Exploiting the native structure and properties of lignin by extraction methods. Chem. Eng. J. 2020, 402, 126237. [CrossRef]

6. Del Buono, D.; Luzi, F.; Puglia, D. Lignin Nanoparticles: A Promising Tool to Improve Maize Physiological, Biochemical, and Chemical Traits. Nanomaterials 2021, 11, 846. [CrossRef]

7. Schutyser, W.; Renders, T.; Van Den Bosch, S.; Koelewijn, S.-F.; Beckham, G.T.; Sels, B.F. Chemicals from lignin: An interplay of lignocellulose fractionation, depolymerisation, and upgrading. Chem. Soc. Rev. 2018, 47, 852-908. [CrossRef]

8. Mirpoor, S.F.; Restaino, O.F.; Schiraldi, C.; Giosafatto, C.V.L.; Ruffo, F.; Porta, R. Lignin/Carbohydrate Complex Isolated from Posidonia oceanica Sea Balls (Egagropili): Characterization and Antioxidant Reinforcement of Protein-Based Films. Int. J. Mol. Sci. 2021, 22, 9147. [CrossRef]

9. Chen, L.; Zhou, X.; Shi, Y.; Gao, B.; Wu, J.-P.; Kirk, T.; Xu, J.; Xue, W. Green synthesis of lignin nanoparticle in aqueous hydrotropic solution toward broadening the window for its processing and application. Chem. Eng. J. 2018, 346, 217-225. [CrossRef]

10. Sohni, S.; Hashim, R.; Nidaullah, H.; Lamaming, J.; Sulaiman, O. Chitosan/nano-lignin based composite as a new sorbent for enhanced removal of dye pollution from aqueous solutions. Int. J. Biol. Macromol. 2019, 132, 1304-1317. [CrossRef] [PubMed]

11. Sun, R. Across the Board: Runcang Sun on Lignin Nanoparticles. ChemSusChem 2020, 13, 4768-4770. [CrossRef]

12. Zhang, Z.; Terrasson, V.; Guénin, E. Lignin Nanoparticles and Their Nanocomposites. Nanomaterials 2021, 11, 1336. [CrossRef] [PubMed]

13. Rizal, S.; Alfatah, T.; HPS, A.K.; Mistar, E.; Abdullah, C.; Olaiya, F.; Sabaruddin, F.; Ikramullah; Muksin, U. Properties and Characterization of Lignin Nanoparticles Functionalized in Macroalgae Biopolymer Films. Nanomaterials 2021, 11, 637. [CrossRef] 
14. Lievonen, M.; Valle-Delgado, J.J.; Mattinen, M.-L.; Hult, E.-L.; Lintinen, K.; Kostiainen, M.A.; Paananen, A.; Szilvay, G.R.; Setälä, H.; Österberg, M. A simple process for lignin nanoparticle preparation. Green Chem. 2016, 18, 1416-1422. [CrossRef]

15. Iravani, S.; Varma, R.S. Greener synthesis of lignin nanoparticles and their applications. Green Chem. 2020, 22, 612-636. [CrossRef]

16. Zhang, X.; Yang, M.; Yuan, Q.; Cheng, G. Controlled Preparation of Corncob Lignin Nanoparticles and their Size-Dependent Antioxidant Properties: Toward High Value Utilization of Lignin. ACS Sustain. Chem. Eng. 2019, 7, 17166-17174. [CrossRef]

17. Österberg, M.; Sipponen, M.H.; Mattos, B.D.; Rojas, O.J. Spherical lignin particles: A review on their sustainability and applications. Green Chem. 2020, 22, 2712-2733. [CrossRef]

18. Nair, S.S.; Sharma, S.; Pu, Y.; Sun, Q.; Pan, S.; Zhu, J.Y.; Deng, Y.; Ragauskas, A.J. High Shear Homogenization of Lignin to Nanolignin and Thermal Stability of Nanolignin-Polyvinyl Alcohol Blends. ChemSusChem 2014, 7, 3513-3520. [CrossRef]

19. Yang, W.; Qi, G.; Ding, H.; Xu, P.; Dong, W.; Zhu, X.; Zheng, T.; Ma, P. Biodegradable poly (lactic acid)-poly ( $\varepsilon$-caprolactone)nanolignin composite films with excellent flexibility and UV barrier performance. Compos. Commun. 2020, 22, 100497. [CrossRef]

20. Yang, W.; Fortunati, E.; Bertoglio, F.; Owczarek, J.; Bruni, G.; Kozanecki, M.; Kenny, J.M.; Torre, L.; Visai, L.; Puglia, D. Polyvinyl alcohol/chitosan hydrogels with enhanced antioxidant and antibacterial properties induced by lignin nanoparticles. Carbohydr. Polym. 2018, 181, 275-284. [CrossRef]

21. Zhou, Y.; Han, Y.; Li, G.; Yang, S.; Chu, F. Lignin-Based Hollow Nanoparticles for Controlled Drug Delivery: Grafting Preparation Using $\beta$-Cyclodextrin/Enzymatic-Hydrolysis Lignin. Nanomaterials 2019, 9, 997. [CrossRef] [PubMed]

22. Ferro, C.; Kemell, M.; Liu, Z.; Kiriazis, A.; Lintinen, K.; Florindo, H.F.; Yli-Kauhaluoma, J.; Hirvonen, J.; Kostiainen, M.A.; Santos, H.; et al. Functionalization of Carboxylated Lignin Nanoparticles for Targeted and Ph-Responsive Delivery of Anticancer Drugs. Nanomedicine 2017, 21, 2581-2596.

23. Kwak, H.W.; Shin, M.; Yun, H.; Lee, K.H. Preparation of Silk Sericin/Lignin Blend Beads for the Removal of Hexavalent Chromium Ions. Int. J. Mol. Sci. 2016, 17, 1466. [CrossRef]

24. Henn, A.; Mattinen, M.-L. Chemo-enzymatically Prepared Lignin Nanoparticles for Value-added Applications. World J. Microbiol. Biotechnol. 2019, 35, 125. [CrossRef]

25. Ju, T.; Zhang, Z.; Li, Y.; Miao, X.; Ji, J. Continuous production of lignin nanoparticles using a microchannel reactor and its application in UV-shielding films. RSC Adv. 2019, 9, 24915-24921. [CrossRef]

26. Frangville, C.; Rutkevičius, M.; Richter, A.P.; Velev, O.D.; Stoyanov, S.D.; Paunov, V.N. Fabrication of Environmentally Biodegradable Lignin Nanoparticles. ChemPhysChem 2012, 13, 4235-4243. [CrossRef] [PubMed]

27. Chen, Y.; Jiang, Y.; Tian, D.; Hu, J.; He, J.; Yang, G.; Luo, L.; Xiao, Y.; Deng, S.; Deng, O.; et al. Fabrication of spherical lignin nanoparticles using acid-catalyzed condensed lignins. Int. J. Biol. Macromol. 2020, 164, 3038-3047. [CrossRef]

28. Beisl, S.; Friedl, A.; Miltner, A. Lignin from Micro- to Nanosize: Applications. Int. J. Mol. Sci. 2017, 18, 2367. [CrossRef] [PubMed]

29. Pang, T.; Wang, G.; Sun, H.; Wang, L.; Liu, Q.; Sui, W.; Parvez, A.M.; Si, C. Lignin Fractionation for Reduced Heterogeneity in Self-Assembly Nanosizing: Toward Targeted Preparation of Uniform Lignin Nanoparticles with Small Size. ACS Sustain. Chem. Eng. 2020, 8, 9174-9183. [CrossRef]

30. Posoknistakul, P.; Tangkrakul, C.; Chaosuanphae, P.; Deepentham, S.; Techasawong, W.; Phonphirunrot, N.; Bairak, S.; Sakdaronnarong, C.; Laosiripojana, N. Fabrication and Characterization of Lignin Particles and Their Ultraviolet Protection Ability in PVA Composite Film. ACS Omega 2020, 5, 20976-20982. [CrossRef] [PubMed]

31. Tian, D.; Hu, J.; Bao, J.; Chandra, R.P.; Saddler, J.N.; Lu, C. Lignin valorization: Lignin nanoparticles as high-value bio-additive for multifunctional nanocomposites. Biotechnol. Biofuels 2017, 10, 192. [CrossRef] [PubMed]

32. Xiong, F.; Han, Y.; Wang, S.; Li, G.; Qin, T.; Chen, Y.; Chu, F. Preparation and Formation Mechanism of Renewable Lignin Hollow Nanospheres with a Single Hole by Self-Assembly. ACS Sustain. Chem. Eng. 2017, 5, 2273-2281. [CrossRef]

33. Chen, L.; Shi, Y.; Gao, B.; Zhao, Y.; Jiang, Y.; Zha, Z.; Xue, W.; Gong, L. Lignin Nanoparticles: Green Synthesis in a $\gamma-$ Valerolactone/Water Binary Solvent and Application to Enhance Antimicrobial Activity of Essential Oils. ACS Sustain. Chem. Eng. 2020, 8, 714-722. [CrossRef]

34. Lou, R.; Ma, R.; Lin, K.-T.; Ahamed, A.; Zhang, X. Facile Extraction of Wheat Straw by Deep Eutectic Solvent (DES) to Produce Lignin Nanoparticles. ACS Sustain. Chem. Eng. 2019, 7, 10248-10256. [CrossRef]

35. Xue, B.; Yang, Y.; Tang, R.; Xue, D.; Sun, Y.; Li, X. Efficient dissolution of lignin in novel ternary deep eutectic solvents and its application in polyurethane. Int. J. Biol. Macromol. 2020, 164, 480-488. [CrossRef]

36. Chen, Z.; Bai, X.; Zhang, H.; Wan, C. Insights into Structural Changes of Lignin toward Tailored Properties during Deep Eutectic Solvent Pretreatment. ACS Sustain. Chem. Eng. 2020, 8, 9783-9793. [CrossRef]

37. Sosa, F.H.B.; Abranches, D.O.; Lopes, A.M.D.C.; Coutinho, J.A.P.; Da Costa, M.C. Kraft Lignin Solubility and Its Chemical Modification in Deep Eutectic Solvents. ACS Sustain. Chem. Eng. 2020, 8, 18577-18589. [CrossRef]

38. Hong, S.; Shen, X.-J.; Xue, Z.; Sun, Z.; Yuan, T.-Q. Structure-function relationships of deep eutectic solvents for lignin extraction and chemical transformation. Green Chem. 2020, 22, 7219-7232. [CrossRef]

39. Das, L.; Li, M.; Stevens, J.C.; Li, W.; Pu, Y.; Ragauskas, A.J.; Shi, J. Characterization and Catalytic Transfer Hydrogenolysis of Deep Eutectic Solvent Extracted Sorghum Lignin to Phenolic Compounds. ACS Sustain. Chem. Eng. 2018, 6, 10408-10420. [CrossRef]

40. Naghshineh, N.; Tahvildari, K.; Nozari, M. Preparation of Chitosan, Sodium Alginate, Gelatin and Collagen Biodegradable Sponge Composites and their Application in Wound Healing and Curcumin Delivery. J. Polym. Environ. 2019, 27, 2819-2830. [CrossRef] 
41. Bilal, M.; Iqbal, H.M. Lignin peroxidase immobilization on Ca-alginate beads and its dye degradation performance in a packed bed reactor system. Biocatal. Agric. Biotechnol. 2019, 20, 101205. [CrossRef]

42. Luo, T.; Wang, C.; Ji, X.; Yang, G.; Chen, J.; Janaswamy, S.; Lyu, G. Preparation and Characterization of Size-Controlled Lignin Nanoparticles with Deep Eutectic Solvents by Nanoprecipitation. Molecules 2021, 26, 218. [CrossRef] [PubMed]

43. Albadarin, A.; Collins, M.; Naushad, M.; Shirazian, S.; Walker, G.; Mangwandi, C. Activated lignin-chitosan extruded blends for efficient adsorption of methylene blue. Chem. Eng. J. 2017, 307, 264-272. [CrossRef]

44. Budnyak, T.M.; Aminzadeh, S.; Pylypchuk, I.V.; Sternik, D.; Tertykh, V.A.; Lindström, M.E.; Sevastyanova, O. Methylene Blue Dye Sorption by Hybrid Materials from Technical Lignins. J. Environ. Chem. Eng. 2018, 6, 4997-5007. [CrossRef]

45. Chen, H.; Qu, X.; Liu, N.; Wang, S.; Chen, X.; Liu, S. Study of the adsorption process of heavy metals cations on Kraft lignin. Chem. Eng. Res. Des. 2018, 139, 248-258. [CrossRef]

46. Zhang, X.; Liu, W.; Liu, W.; Qiu, X. High Performance Pva/Lignin Nanocomposite Films with Excellent Water Vapor Barrier and Uv-Shielding Properties. Int. J. Biol. Macromol. 2020, 142, 551-558. [CrossRef] [PubMed]

47. Shen, X.-J.; Wang, B.; Pan-Li, H.; Wen, J.-L.; Sun, R.-C. Understanding the structural changes and depolymerization of Eucalyptus lignin under mild conditions in aqueous AlCl3. RSC Adv. 2016, 6, 45315-45325. [CrossRef]

48. Malaeke, H.; Housaindokht, M.R.; Monhemi, H.; Izadyar, M. Deep eutectic solvent as an efficient molecular liquid for lignin solubilization and wood delignification. J. Mol. Liq. 2018, 263, 193-199. [CrossRef]

49. Liu, Q.; Zhao, X.; Yu, D.; Yu, H.; Zhang, Y.; Xue, Z.; Mu, T. Novel deep eutectic solvents with different functional groups towards highly efficient dissolution of lignin. Green Chem. 2019, 21, 5291-5297. [CrossRef]

50. Xiong, F.; Han, Y.; Wang, S.; Li, G.; Qin, T.; Chen, Y.; Chu, F. Preparation and formation mechanism of size-controlled lignin nanospheres by self-assembly. Ind. Crop. Prod. 2017, 100, 146-152. [CrossRef]

51. Ma, M.; Dai, L.; Si, C.; Hui, L.; Liu, Z.; Ni, Y. A Facile Preparation of Super Long-Term Stable Lignin Nanoparticles from Black Liquor. ChemSusChem 2019, 12, 5239-5245. [CrossRef] [PubMed]

52. Yan, Z.; Liao, G.; Zou, X.; Zhao, M.; Wu, T.; Chen, Y.; Fang, G. Size-Controlled and Super Long-Term Stable Lignin Nanospheres through a Facile Self-Assembly Strategy from Kraft Lignin. J. Agric. Food Chem. 2020, 68, 8341-8349. [CrossRef] [PubMed]

53. Liu, C.; Li, Y.; Hou, Y. A simple environment-friendly process for preparing high-concentration alkali lignin nanospheres. Eur. Polym. J. 2019, 112, 15-23. [CrossRef]

54. Qian, Y.; Deng, Y.; Qiu, X.; Li, H.; Yang, D. Formation of uniform colloidal spheres from lignin, a renewable resource recovered from pulping spent liquor. Green Chem. 2014, 16, 2156-2163. [CrossRef]

55. Zhong, L.; Xu, M.; Wang, C.; Shao, L.; Mao, J.; Jiang, W.; Ji, X.; Yang, G.; Chen, J.; Lyu, G.; et al. Pretreatment of willow using the alkaline-catalyzed sulfolane/water solution for high-purity and antioxidative lignin production. Int. J. Biol. Macromol. 2020 159, 287-294. [CrossRef]

56. Nair, V.; Panigrahy, A.; Vinu, R. Development of novel chitosan-lignin composites for adsorption of dyes and metal ions from wastewater. Chem. Eng. J. 2014, 254, 491-502. [CrossRef]

57. Li, Y.; Wu, M.; Wang, B.; Wu, Y.; Ma, M.; Zhang, X. Synthesis of Magnetic Lignin-Based Hollow Microspheres: A Highly Adsorptive and Reusable Adsorbent Derived from Renewable Resources. ACS Sustain. Chem. Eng. 2016, 4, 5523-5532. [CrossRef]

58. Wang, X.; Ji, S.-L.; Wang, X.-Q.; Bian, H.-Y.; Lin, L.-R.; Dai, H.-Q.; Xiao, H. Thermally conductive, super flexible and flame-retardant BN-OH/PVA composite film reinforced by lignin nanoparticles. J. Mater. Chem. C 2019, 7, 14159-14169. [CrossRef]

59. Das, P.; Ganguly, S.; Saha, A.; Noked, M.; Margel, S.; Gedanken, A. Carbon-Dots-Initiated Photopolymerization: An in Situ Synthetic Approach for Mxene/Poly(Norepinephrine)/Copper Hybrid and Its Application for Mitigating Water Pollution. ACS Appl. Mater. Inter. 2021, 13, 31038-31050. [CrossRef]

60. Ganguly, S.; Das, P.; Itzhaki, E.; Hadad, E.; Gedanken, A.; Margel, S. Microwave-Synthesized Polysaccharide-Derived Carbon Dots as Therapeutic Cargoes and Toughening Agents for Elastomeric Gels. ACS Appl. Mater. Interfaces 2020, 12, 51940-51951. [CrossRef]

61. Li, Z.; Ge, Y.; Wan, L. Fabrication of a green porous lignin-based sphere for the removal of lead ions from aqueous media. $J$. Hazard. Mater. 2015, 285, 77-83. [CrossRef]

62. Ma, M.; Liu, Z.; Hui, L.; Shang, Z.; Yuan, S.; Dai, L.; Liu, P.; Liu, X.; Ni, Y. Lignin-containing cellulose nanocrystals/sodium alginate beads as highly effective adsorbents for cationic organic dyes. Int. J. Biol. Macromol. 2019, 139, 640-646. [CrossRef]

63. Jin, Y.; Zeng, C.; Lü, Q.-F.; Yu, Y. Efficient adsorption of methylene blue and lead ions in aqueous solutions by 5-sulfosalicylic acid modified lignin. Int. J. Biol. Macromol. 2019, 123, 50-58. [CrossRef]

64. Cemin, A.; Ferrarini, F.; Poletto, M.; Bonetto, L.R.; Bortoluz, J.; Lemée, L.; Guégan, R.; Esteves, V.I.; Giovanela, M. Characterization and use of a lignin sample extracted from Eucalyptus grandis sawdust for the removal of methylene blue dye. Int. J. Biol. Macromol. 2021, 170, 375-389. [CrossRef] [PubMed]

65. Lou, T.; Cui, G.; Xun, J.; Wang, X.; Feng, N.; Zhang, J. Synthesis of a terpolymer based on chitosan and lignin as an effective flocculant for dye removal. Colloids Surfaces A Physicochem. Eng. Asp. 2018, 537, 149-154. [CrossRef]

66. Hu, L.; Guang, C.; Liu, Y.; Su, Z.; Gong, S.; Yao, Y.; Wang, Y. Adsorption behavior of dyes from an aqueous solution onto composite magnetic lignin adsorbent. Chemosphere 2020, 246, 125757. [CrossRef] [PubMed]

67. Mohammed, N.; Grishkewich, N.; Berry, R.M.; Tam, K.C. Cellulose nanocrystal-alginate hydrogel beads as novel adsorbents for organic dyes in aqueous solutions. Cellulose 2015, 22, 3725-3738. [CrossRef] 